\title{
Extension of the algebraic transition model for the wall roughness effect
}

\author{
Petr Straka ${ }^{1, a}$, Jaromír Príhoda ${ }^{2}$ \\ ${ }^{1}$ Aerospace Research and Test Establishment, Plc, Prague, Czech Republic \\ ${ }^{2}$ Institute of Thermomechanics AS CR, v.v.i., Prague, Czech Republic
}

\begin{abstract}
The contribution deals with the simulation of the laminar/turbulent transition taking into account the effect of wall roughness. The correlation for the transition onset proposed by Straka and Př́hoda [1] was modified for the effect of the wall roughness using the correlation according to Boyle and Stripf [2]. This correlation derived for the wall roughness formed by regularly distributed truncated cones was modified for flows over the distributed wall roughness. The algebraic transition model proposed by Straka and Př́hoda [1] with the modified relation for the transition onset was verified by means of the incompressible flat-plate boundary-layer and the compressible flow through the turbine blade cascade with rough blades.
\end{abstract}

\section{Introduction}

Besides the pressure gradient, the laminar-turbulent transition in turbomachinery flows is mostly influenced by the free-stream turbulence and wall roughness. Most models of the bypass transition take into account the effect of the free-stream turbulence and the pressure gradient only. The simulation of compressible flows through turbine blade cascades has to take into account many factors, especially the effect of pressure gradient, free-stream turbulence, and wall roughness. The mathematical model should not be completed by the turbulence model only, but also by adequate models of the laminar/turbulent transition and turbulent heat transfer.

The majority of inner surfaces are rough due to erosion and deposits during operation. A typical example is the surface of turbine blades. An extensive review on the effect of wall roughness on flows in turbines was given e.g. by Bons [3]. Typical roughness of operational turbine blades was measured and studied by Bogard et al. [4].

While the wall roughness effect on the modelling of turbulent flow is sufficiently described, the reliable relations for the laminar/turbulent transition on rough walls are very rare. Many publications on the effect of roughness on the transition onset deal with the acceleration of the transition by means of locally placed roughness elements as wires and/or strips of sandpaper near the leading edge of airfoils. Much less experimental results were accomplished for flows over walls with distributed roughness.

The contribution deals with a short review of existing correlations for the transition onset including a modified criterion of Boyle and Stripf [2] and with its testing by means of selected test cases - incompressible flat plate flow and compressible flows through a linear turbine blade cascade.

\section{Modelling of wall roughness effect}

For turbulent flow, wall roughness is mostly model-led by the $k-\omega$ turbulence models with wall boundary condition for the specific dissipation rate $\omega$ proposed by Wilcox [5] and lately modified by Hellsten [6] and/or by a two/layer $k-L / k-\varepsilon$ turbulence model according to Cebeci and Chang [7], see e.g. Stripf et al. [8].

The roughness of various types is usually described by the centreline averaged roughness $R a$ or the average peak to valley roughness $R z$. The equivalent sand roughness $k_{s}$ introduced by Nikuradse [9] is mainly used for numerical simulations. According to Bogard et al. [4], roughness parameters of operational turbine blades were in the range $R a=8 \div 46 \mu \mathrm{m}$ in contrast to new blades with typical value of $R a=1.5 \mu \mathrm{m}$. The correlations $k_{s} \approx$ $(5 \div 6) R a$ can be used for blade surface roughness.

Most of correlations for the wall roughness effect on the transition onset are extensions or modifications of existing relations for transition on smooth walls. Besides, another approach is based on the discrete element model. This roughness model combined with a two-layer turbulence model was used for transition modelling by Stripf et al. $[8,10]$.

One of first correlations for the transition onset was proposed by Mayle [11] in the form

$$
R e_{\theta t r}=100+0.43 \exp \left[7-0.77\left(k_{s} / \theta_{t}\right)\right]
$$

A very extensive investigation of the wall roughness effect on the transition was carried out by Stripf et al. [12] and Stripf [13] on rough turbine blades with heat

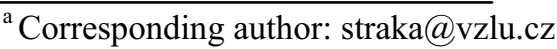


transfer. Wall roughness on turbine blades was modelled by regularly distributed truncated cones with various distances. Several correlations were proposed based on these experiments. Stripf et al. [8] proposed a correlation for the transition onset on rough walls with the height of cones $k$ and the density parameter $\Lambda_{R}$ used for the description of roughness. Stripf et al. [10] slightly modified the initial correlation to the form

$$
R e_{\theta t r}=\left[\frac{1}{R e_{\theta t}}+0.0061 f_{\Lambda}\left(\frac{k}{\delta_{t}^{*}}-0.01\right)^{f_{T u}}\right]^{-1}
$$

valid for $0.01<k / \delta_{t}^{*} \leq 3$. The relation for the transition onset on a smooth wall is given by the relation

$$
R e_{\theta t}=500 T u_{e f}^{-0.75}
$$

The effect of free-stream turbulence level is expressed by the function $f_{T u}$ with the maximum $f_{\text {Tumax }}=0.9$ and the effect of the element spacing by the function $f_{\Lambda}$. The maximal value $f_{\text {Amax }}=1$ is recommended for the distributed roughness.

Similarly Langtry and Menter [14] presented a modification of the $\gamma$-Re transition model for flow over rough walls based on experiments of Stripf et al. [12]. The proposed correlation

$$
R e_{\theta t r}=R e_{\theta t} \min \left[1 ; \frac{0.0554+1.005\left(\theta_{t} / k\right)^{0.87}}{1.4629+\left(\theta_{t} / k\right)^{0.87}}\right]
$$

was tested by means of experimental data of Stripf et al. [12] and measurement of Pimenta et al. [15] on a flat plate with tightly packed spheres.

Boyle and Stripf [2] came out from the simple criterion for the transition onset due to free-stream turbulence

$$
R e_{\theta t}=400 T u^{-0.625}
$$

proposed by Mayle [11]. The effect of wall roughness on the transition onset was expressed by the correlation

$$
R e_{\theta t r}=\frac{R e_{\theta t}}{1+T u^{-0.625}\left[0.05\left(k_{s}^{+}-5\right)\right]^{1.25}}
$$

According to the investigation of turbulent boundary layer on a rough wall, the surface is hydraulically smooth for the equivalent sand-grain roughness $k_{s}^{+}<5$. The proposed correlation was used for the modelling of flow through the turbine blade cascade with roughness formed by truncated cones according to experiments of Stripf et al. [12] by means of the two-layer $k-\varepsilon / k-L$ turbulence model.

The latest correlation of the effect of wall roughness and free stream turbulence on the transition onset was proposed by Lorenz et al. [16]. However, this correlation is as well based on the investigation of the heat transfer in turbine blade cascades with roughness formed by truncated cones.

The empirical correlations for the transition onset due to wall roughness should be generally applicable for various types of wall roughness. Turbulence models modified for flow on rough walls are based on the nondimensional equivalent sand grain roughness $k_{s}^{+}$. The application of the friction velocity as the parameter is not suitable for the numerical simulation especially in the transitional flow. The more convenient parameter is the ratio $k_{s} / \theta_{t}$ introduced by Mayle [11]. Provided that the Blasius boundary layer exists in the laminar part of the boundary layer, the non-dimensional equivalent sandgrain roughness can be correlated to the ratio $k_{s} / \theta$ by the relation $k_{s}^{+}=0.4695 \operatorname{Re}_{\theta}{ }^{1 / 2} k_{s} / \theta$.

The transition criterion of Boyle and Stripf [2] modified to the relation $R e_{\theta t r}=\mathrm{f}\left(T u, k_{s} / \theta_{t}\right)$ is compared in figure 1 with the accessible experimental data. The lower limit of rough wall $k_{s}^{+}=5$ is denoted by the dashed line.

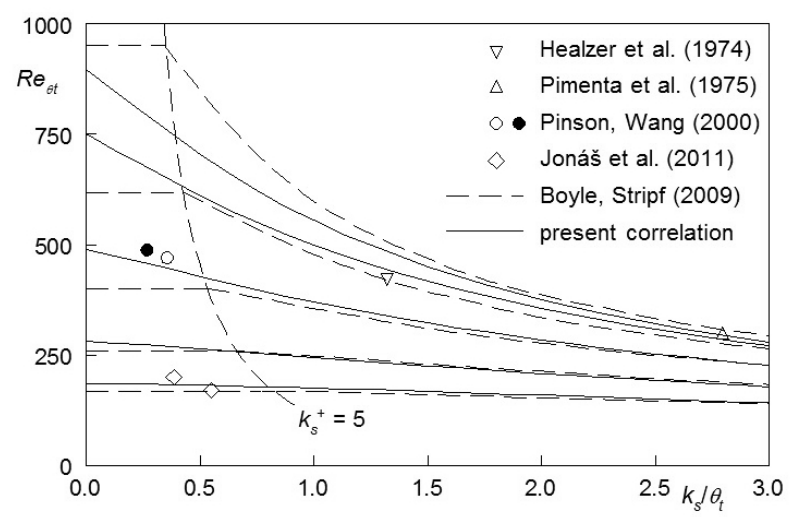

Figure 1. Modified transition correlation for rough walls

Nevertheless, results of experimental investigation of the transition on a rough flat plate with sand paper carried out by Pinson and Wang [17] and Jonáš et al. [18] show that the wall roughness influences the transition onset for values $k_{s}^{+}<5$. Therefore, the transition correlation of Boyle and Stripf [2] was modified to the form

$$
\operatorname{Re}_{\theta t r}=\frac{R e_{\theta t}}{1+F_{r}\left(T u, k_{s} / \theta_{t}\right)},
$$

where the function $F_{r}$ is approximated by the relation

$$
\begin{gathered}
F_{r}=a\left(k_{s} / \theta_{t}\right)^{b} \quad \text { for } k_{s} / \theta_{t} \leq 3 \\
F_{r}=c_{0}+c_{1} \frac{k_{s}}{\theta_{t}}+c_{2}\left(\frac{k_{s}}{\theta_{t}}\right)^{2} \quad \text { for } k_{s} / \theta_{t}>3
\end{gathered}
$$

Coefficients $a, b, c_{0}, c_{1}$ and $c_{2}$ are dependent on the free-stream turbulence level. The correlation for the transition onset on a smooth wall $\operatorname{Re}_{\theta t}=(T u, \lambda)$ was used according to Straka and Prríhoda [1].

\section{Mathematical model}

The Favre-averaged Navier-Stokes equations are closed by the EARSM model according to Hellsten [19] connected with the algebraic transition model proposed by Straka and Prríhoda [1]. The Reynolds stress in the EARSM model is expressed by the anisotropy tensor

$$
a_{i j}=\frac{\tau_{i j}}{k}-\frac{2}{3} \delta_{i j}
$$

Transport equations for the turbulent energy $k$ and the specific dissipation rate $\omega$ are used in the two-layer form with two sets of model coefficients and with the blending function according to Menter [20] in the form

$$
\frac{D(\rho k)}{D t}=P_{k}-\beta^{*} \rho \omega k+\frac{\partial}{\partial x_{j}}\left[\left(\mu+\sigma_{k} \mu_{t}\right) \frac{\partial k}{\partial x_{j}}\right]
$$




$$
\frac{D(\rho \omega)}{D t}=\frac{\gamma \omega}{k} P_{k}-\beta \rho \omega^{2}+\frac{\partial}{\partial x_{j}}\left[\left(\mu+\sigma_{\omega} \mu_{t}\right) \frac{\partial \omega}{\partial x_{j}}\right]+C_{D}
$$

Turbulent viscosity is given by the relation

$$
\mu_{t}=C_{\mu} \rho k \tau_{t}
$$

with the turbulent time scale

$$
\tau_{t}=\max \left(\frac{1}{\beta^{*} \omega} ; C_{\tau} \sqrt{\frac{v}{\beta^{*} \omega k}}\right),
$$

where the Kolmogorov viscous time scale is used near the wall. The variable coefficient $C_{\mu}$ is obtained by

$$
C_{\mu}=-\left(\beta_{1}+I I_{\Omega} \beta_{6}\right) / 2
$$

For the reduction of the undesirable overproduction of the turbulent energy in the stagnation region, the production term in the turbulent energy equation was modified into form

$$
P_{k}=\psi\left(\tau_{i j} \frac{\partial \bar{U}_{i}}{\partial x_{j}}\right)+(1-\psi) \mu_{t} \Omega^{2},
$$

where $\tau_{i j}$ is the Reynolds stress tensor and $\Omega$ is the absolute value of the vorticity tensor. The parameter $\psi$ is given by the relation

$$
\psi=1-\max \left[\min \left(C_{\psi} \tau_{t}\left|S^{2}-\Omega^{2}\right| ; 1\right) ; 0\right]
$$

with $C_{\psi}=0.05 \div 0.2$. The parameter $\psi$ is equals to 1 nearly in the all computational domain except the vicinity of the stagnation point where decreases to zero.

The turbulent heat transfer is modelled according to Launder [21] by the generalized gradient hypothesis in the form

$$
-\overline{u_{i} t}=C_{t} \frac{\tau_{i j}}{\omega} \frac{\partial \bar{T}}{\partial x_{j}}
$$

with constant $C_{t}=0.3$

For the prediction of the transitional flows, the production and destruction terms in the $k$-equation are multiplied by the intermittency coefficient $\gamma$. Similarly, the effective viscosity is given by $\mu_{e f}=\mu+\gamma \mu_{t}$ in the transition region.

The algebraic transition model is based on the concept of different values of the intermittency coefficient in the boundary layer $\gamma_{i}$ and in the free stream $\gamma_{e}$. The intermittency coefficient in the boundary layer is given by the relation

$$
\gamma_{i}=1-\exp \left[-\hat{n} \sigma\left(R e_{x}-R e_{x t}\right)^{2}\right]
$$

proposed by Narasimha [22]. The transition onset is given by the momentum Reynolds number $R e_{x t}$ usually depending on the free-stream turbulence level $T u(\%)$ and the pressure-gradient parameter $\lambda_{t}=\left(\theta_{t}^{2} / v\right)\left(\mathrm{d} U_{e} / \mathrm{d} x\right)$ at the transition onset. The used empirical correlation is given by the relation

$$
R e_{\theta t}=R e_{\theta t o}\left[1+F(T u) \frac{1-\exp (-40 \lambda)}{1+0.4 \exp (-40 \lambda)}\right],
$$

where the transition onset on the flat plate without pressure gradient is given by the relation

$$
R e_{\theta t o}=975.8-497.2 T u+\frac{11.4}{T u} \text { for } T u \leq 1 \%
$$

$$
R e_{\theta t o}=96.7+\frac{340}{T u}+\frac{53.3}{T u^{2}} \quad \text { for } T u>1 \%
$$

The function $F(T u)$ is given by the relation

$$
F(T u)=0.29[1-0.54 \exp (-3.5 T u)] \exp (-T u)
$$

The length of the transition region given by the spot generation rate $\hat{n}$ and the spot propagation rate $\sigma$ is expressed using the parameter $N=\hat{n} \sigma R e_{\theta t}{ }^{3}$ introduced by Narasimha [23]. The effect of the free-stream turbulence and the pressure gradient on the parameter $N$ is correlated by an empirical relation $N=\mathrm{f}\left(T u, \lambda_{t}\right)$ proposed for the attached flow by Solomon et al. [24].

The onset of transition in separated flow is given by the correlation proposed by Mayle [11] in the form

$$
R e_{x t}=300 R e_{\theta s}^{0.7}+R e_{x s},
$$

where $R e_{\theta s}$ is the momentum Reynolds number at the separation and $R e_{x s}$ is the Reynolds number related to the distance of the separation position from the leading edge. The transition length is expressed in the form

$$
\hat{n} \sigma=2.28 \times 10^{-5} R e_{\theta s}^{-1.4}
$$

and so the same approach can be applied as in the attached flow.

According to Langtry and Menter [25], the maximum of the vorticity Reynolds number $R e_{\text {vmax }}$ is used to avoid the calculation of the momentum Reynolds number $R e_{\theta}$ in complex flow geometries. The vorticity Reynolds number is given by the relation

$$
R e_{v}=y^{2}|\Omega| / v
$$

where $y$ is the distance from the wall and $\Omega$ is the absolute value of the vorticity tensor. The link between both Reynolds numbers is expressed by the relation $R e_{\theta}=$ $R e_{\text {vmax }} / C$ where the parameter $C$ depends on the pressure gradient. Free-stream turbulence was taken at the boundary layer thickness $\delta$ estimated by means of the position of the maximum vorticity Reynolds number using the similar solutions of Falkner and Skan [26].

The algebraic model was implemented into the inhouse numerical code. The code is based on the finite volume method of the cell-centered type with the Osher'sSolomon's approximation of the Riemann solver and the two-dimensional linear reconstruction with the Van Albada's limiter. The governing equations are discretized using a multi-block quadrilateral structured grid with a block overlapping implementation. The algebraic transition model is described in detail by Fürst et al. [27].

\section{Results}

The modified algebraic transition model was tested by means of incompressible flow over a flat plate covered by sand paper. Further, the transition model was applied for modelling of compressible flow through the linear turbine blade cascade with wall roughness formed by the carborundum powder.

Experiments of Pinson and Wang [28] on a heated flat plate were focused on the effect of wall roughness on the boundary layer development on the heat transfer and skin friction at various configurations of the leading edge and wall roughness. The experiments were conducted on 
smooth wall and on rough wall covered by the 100-grit sand paper. Measurements were carried out at the freestream velocity $U_{e}=8.6$ and $16.1 \mathrm{~m} / \mathrm{s}$ on the smooth wall and $U_{e}=8.6 \mathrm{~m} / \mathrm{s}$ on the rough wall. The free-stream turbulence is about $T u=0.7 \%$ in the test section. The wall roughness is characterized by the centreline averaged roughness $R_{a}=37 \mu \mathrm{m}$ for the grit 100 . The equivalent sand roughness was established by means of the relation $k_{s}=6 R_{a}$ according to Koch and Smith [29]. The difference between wall and free-stream temperature $T_{w}$ $T_{e}=8 \mathrm{deg}$ was used for heat transfer modelling.

The computational domain corresponds to the experimental arrangements. Standard inlet and outlet boundary conditions were applied. The predicted skin friction coefficient $C_{f}$ is compared in figure 2 with experimental data for smooth and rough walls. A quite good agreement was achieved for both cases even though values of $C_{f}$ for the turbulent boundary layer are higher than standard values. Due to the wall roughness, the transition onset moves upstream from $R e_{x t} \approx 9.2 \times 10^{5}$ on smooth wall to $R e_{x t} \approx$ $4.8 \times 10^{5}$ on rough wall at same flow conditions.

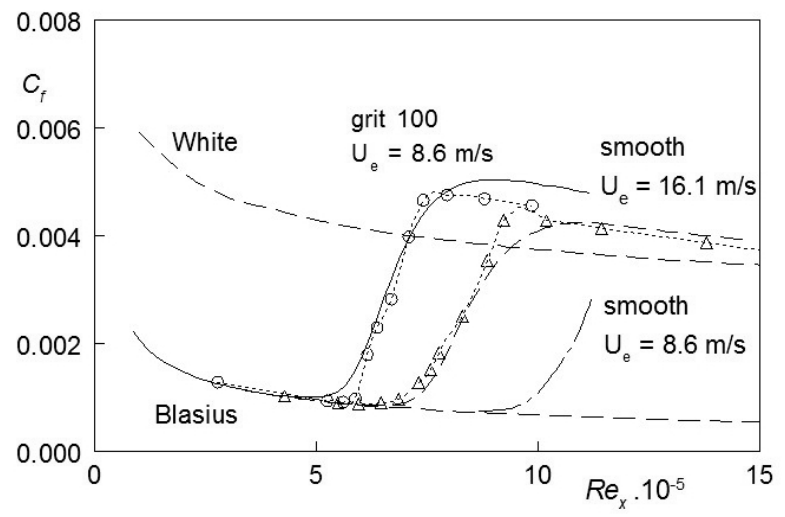

Figure 2. Skin friction distribution on the flat plate

Mean velocity profiles typical for the laminar, transitional and turbulent part of the boundary layer are demonstrated in figure 3 for smooth wall and in figure 4 for rough wall. The agreement of predicted laminar and turbulent velocity profiles with the experimental data is quite good for both cases.

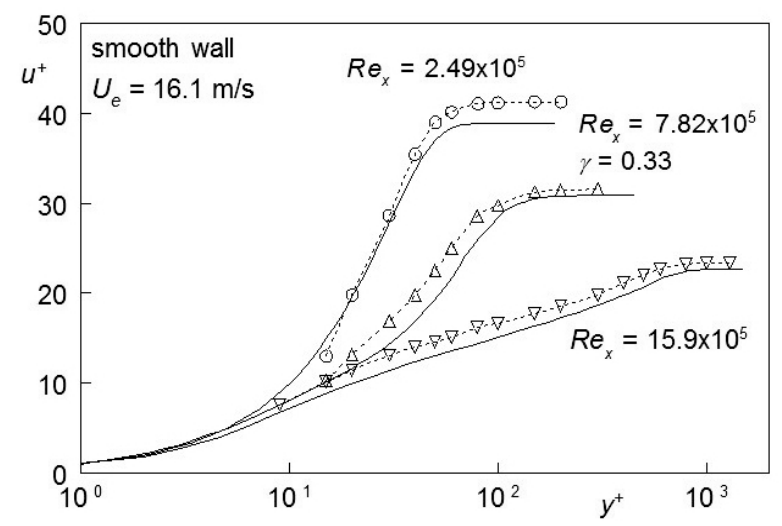

Figure 3. Mean velocity profiles on a smooth wall

For transitional flows the velocity profiles were chosen for Reynolds numbers $R e_{x}$ where the measured inter-mittency coefficient $\gamma$ is about $0.3 \div 0.4$. The predicted velocity profiles correspond to the higher predicted inter-mittency coefficient $\gamma$ as can be seen in figure 5 .

The distribution of the intermittency coefficient $\gamma$ in the inner part of the boundary layer is shown for both cases in figure 5. It follows for the distribution of the intermittency coefficient that measured transition length is somewhat shorter than the predicted one.

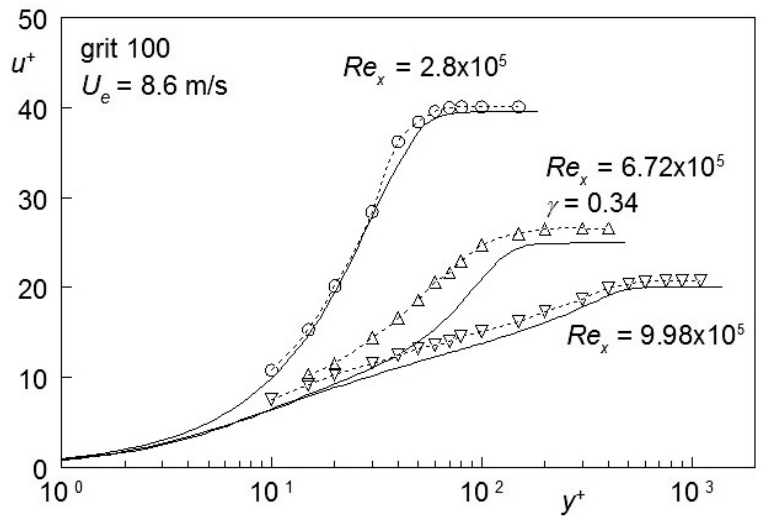

Figure 4. Mean velocity profiles on a rough wall

According to Boyle and Stripf [2], the correlation for the transition length was not modified for roughness effects. This assumption should be probably revised.

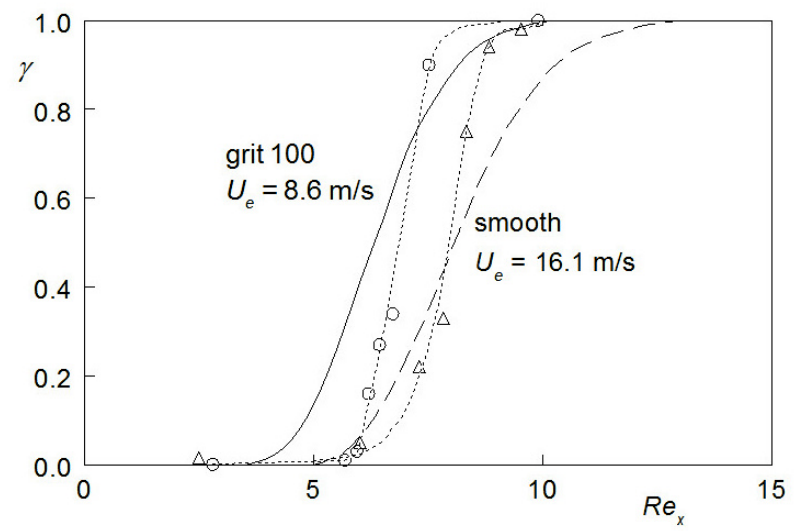

Figure 5. Distribution of the intermittency coefficient

The numerical simulation of 2D compressible flow through the linear turbine blade cascade VS-33 with the relative spacing $t / c=0.7$ and the inlet angle $\alpha_{1}=0^{\circ}$ (smooth blades) and $6^{\circ}$ (rough blades) was carried out for the isentropic Reynolds number $R e_{2 i s}=8.5 \times 10^{5}$ and for isentropic Mach numbers $M_{2 i s}$ from 0.5 up to 0.9. Results were compared with experimental data according to Ulrych et al. [30] and Kladrubský [31]. The wall roughness was created by carborundum powder with $R a$ $=10 \mathrm{and} /$ or 30 deposited on the blade surface. The relation $k_{s}=4.8 R a$ was used for modelling of wall roughness.

For the subsonic flow, the total pressure, the total temperature, the inlet turbulence intensity $T u \approx 4.8 \%$ and the viscosity ratio $\mu_{t} / \mu \approx 100$ were given. At the outlet boundary, the constant static pressure determined according to the outlet isentropic Mach number was prescribed.

The flow field is shown by means of Mach number isolines in figure 6 for values $R e_{2 i s}=8.5 \times 10^{5}$ and $M_{2 i s}=$ 0.9 for the smooth wall and for the rough wall $R a=30$ 


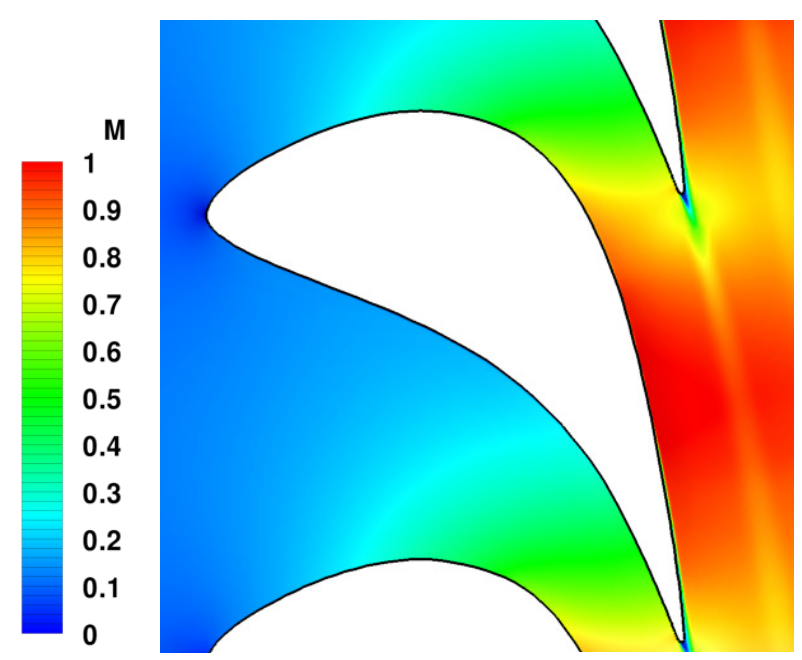

a) smooth wall

Figure 6. Mach number isolines for $M_{2 i s}=0.9$

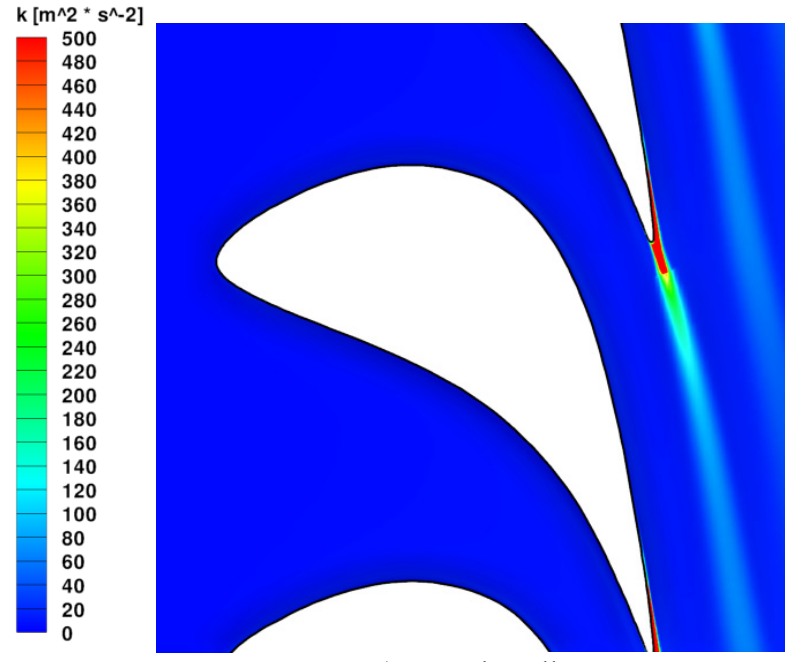

a) smooth wall

Figure 7. Field of turbulent energy for $M_{2 i s}=0.9$

$\mu \mathrm{m}$. The effect of wall roughness is evident especially on the blade suction side and in the wake behind blades.

The field of turbulent energy in the turbine blade cascade is shown in figure 7 for the smooth wall and for the rough wall $R a=30 \mu \mathrm{m}$. The thickness of shear layers on the suction side and the wake is much higher for the rough wall than for the smooth wall.

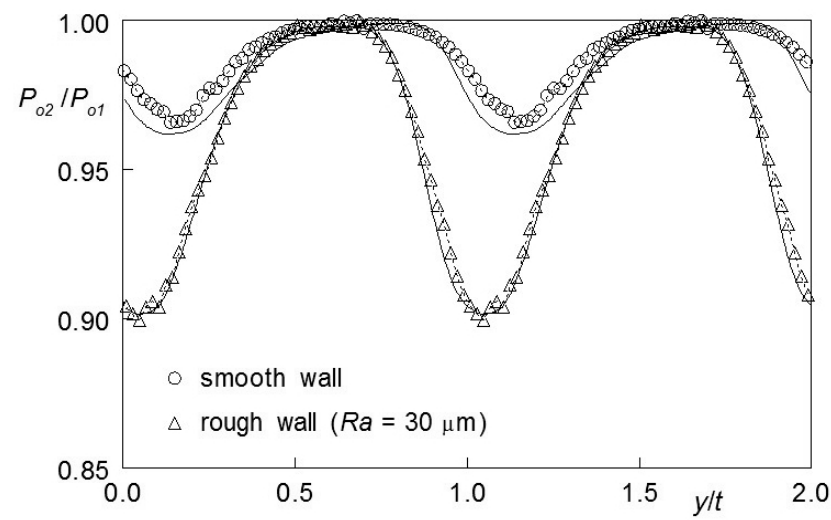

Figure 8. Distribution of the relative total pressure in the wake for $M_{2 i s}=0.9$

The distribution of the relative total pressure in the wake behind the cascade is shown in figure 8 for the

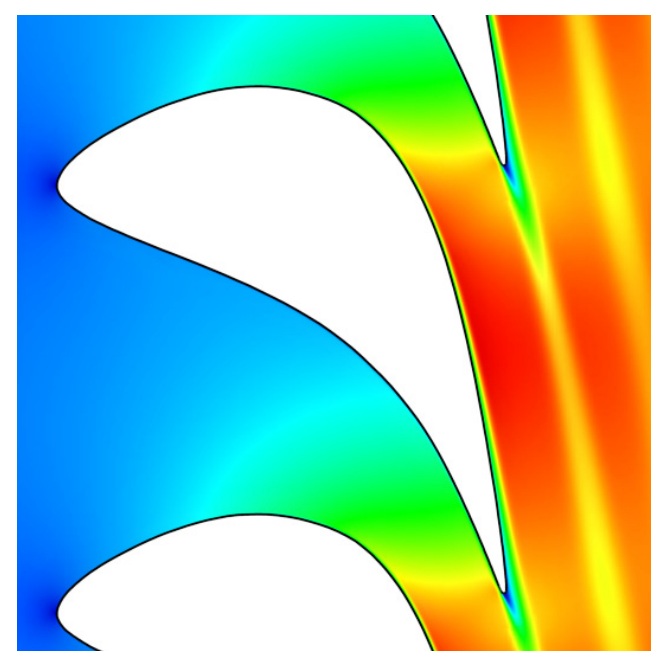

b) rough wall $(R a=30 \mu \mathrm{m})$

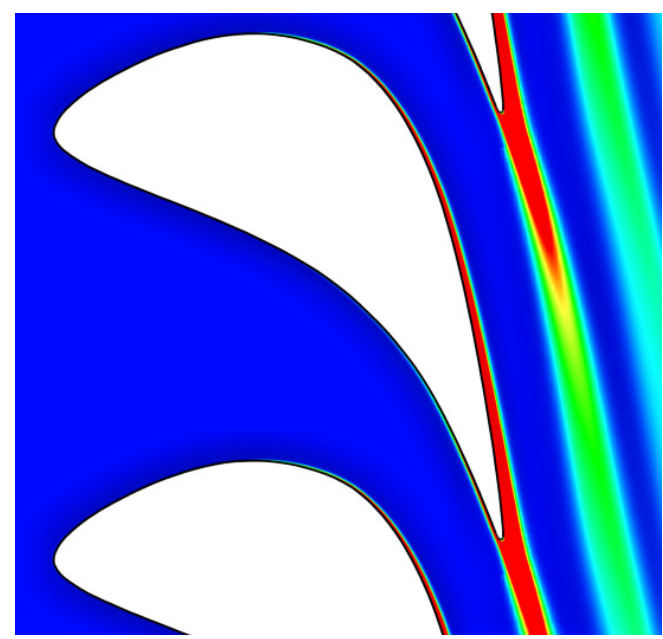

b) rough wall $(R a=30 \mu \mathrm{m})$

Mach number $M_{2 i s}=0.9$. This distribution corresponds to mean velocity profiles behind blades. Numerical results are compared with experimental data obtained in the traversing plane $15 \mathrm{~mm}$ behind the cascade. The agreement with experimental data is quite good.

Finally, predicted loss coefficient $\zeta$ was compared with experimental data for the cascade with smooth and rough blades. The mean values of the loss coefficient across the blade spacing were obtained by the data reduction method, see Amecke and Šafaŕík [32]. The loss coefficient $\zeta$ is defined by the relation

$$
\zeta=1-\left(\frac{U_{2}}{U_{2 i s}}\right)^{2},
$$

where $U_{2}$ is the mean outlet velocity and $U_{2 i s}$ is the mean outlet isentropic velocity. The variation of the loss coefficient with the isentropic Mach number $M_{2 i s}$ for the isentropic Reynolds number $R e_{2 i s}=8.5 \times 10^{5}$ is shown in figure 9. The loss coefficient in the subsonic region slowly decreases with the increasing Mach number. The agreement of the prediction of energy losses carried out by the modified transition model connected with the EARSM model is very good up to $M_{2 i s}=0.9$ for smooth and rough blades as well. In the transonic region, the agreement of predicted and measured data is worse. 


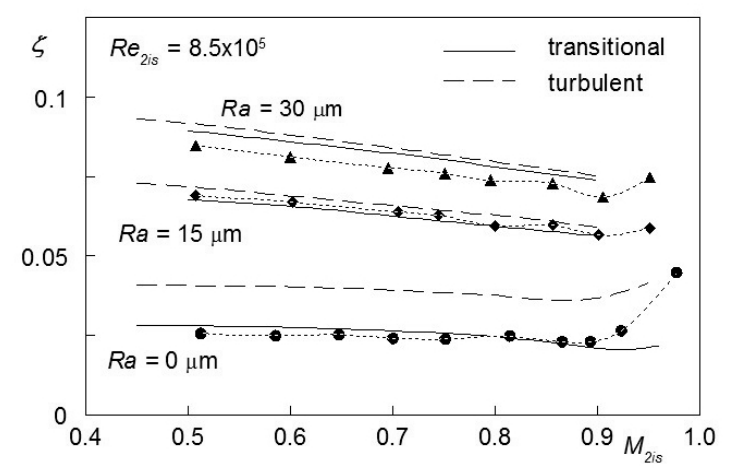

Figure 9. Variation of the loss coefficient with $M_{2 i s}$

In case of smooth blades, the application of the turbulence model only gives energy losses about 50\% higher than the prediction with the transition model. The effect of the transition model on predicted losses is much lesser for rough blades. It is caused to some extent by combined effects of wall roughness and relatively high free-stream turbulence about $T u \approx 4.8 \%$.

\section{Conclusions}

The algebraic transition model was extended for flows over rough walls. The modified model was verified by means of the incompressible flat-plate boundary-layer and the compressible flow through the turbine blade cascade with rough blades. The agreement of numerical results with experimental data is in the both cases quite good. Nevertheless, the measured transition length is somewhat shorter than the predicted one for the flat-plate flow. According to other transition models, the correlation for the transition length was not modified for the effect of roughness. This assumption should be probably revised. As well, the modified model should be further tested for the transition in various boundary conditions.

\section{Acknowledgement}

The work was supported by the institutional support RVO 61388998 and by grants TA CR TA03020277 and GA CR P101/12/1271.

\section{References}

1. P. Straka, J. Příhoda, Proc. Conf. Experimental Fluid Mechanics, Liberec, 636-641 (2010)

2. R. J. Boyle, M. Stripf, Jour. Turbomachinery, 131, 041020 (2009)

3. J. P. Bons, Jour. Turbomachinery, 132, 021004, (2010)

4. D. G. Bogard, D. L. Schmidt, M. Tabbita, Jour. Turbomachinery, 120, 337-342 (1998)

5. D. C. Wilcox, AIAA Jour., 32, 247-255 (1994)

6. A. Hellsten, Some improvements in Menter's $k$ - $\omega$ SST turbulence model, AIAA Paper 28-2554 (1998)

7. T. Cebeci, K. C. Chang, AIAA Jour., 16, 730-735 (1978)

8. M. Stripf, A. Schulz, H.-J. Bauer, Jour. Turbomachinery, 130, 021003 (2008)
9. J. Nikuradse, Forsch.-Arb. Ing.-Wes., 361, (1933)

10. M. Stripf, A. Schulz, H.-J. Bauer, S. Wittig, Jour. Turbomachinery, 131, 031016, 031017 (2009)

11. R. E. Mayle, Jour. Turbomachinery, 113, 509-537 (1991)

12. M. Stripf, A. Schulz, S. Wittig, Jour. Turbomachinery, 127, 200-208 (2005)

13. M. Stripf, Einfluss der Oberflächenrauigkeit auf die transitionale Grenzschicht an Gasturbinen-schaufeln, Dissertation, Universität Karlsruhe (2007)

14. R. Langtry, F. R. Menter, Overview of industrial transition modelling in CFX, Technical Report ANSYS, 172 p. (2006)

15. J. J. Pimenta, R. J. Moffat, W. M. Kays, The turbulent boundary layer: An experimental study of the transport of momentum and heat with the effect of roughness, Report HMT-21, Dept. of Mech. Eng., Stanford University (1975)

16. M. Lorenz, A. Schulz, H.-J. Bauer, ASME Paper GT2012-68910 (2012)

17. M. V. Pinson, T. Wang, Jour. Turbomachinery, 122, 301-307, 308-316 (2000)

18. P. Jonáš, O. Hladík, O. Mazur, V. Uruba, IOP Publishing, Journal of Physics, Conference Series, 318, 032030 (2011)

19. A. Hellsten, New two-equation turbulence model for aerodynamics applications, $\mathrm{PhD}$. Thesis, Helsinki University of Technology (2004)

20. F. R. Menter, AIAA Jour., 32, 1598-1605 (1994)

21. B. E. Launder, Jour. Heat Transfer, 110, 1112-1128 (1988)

22. R. Narasimha, Jour. Aerospace Science, 24, 711-712 (1957)

23. R. Narasimha, Prog. Aerospace Science, 22, 29-80, (1985)

24. W. J. Solomon, G. J. Walker, J. P. Gostelow, Jour. Turbomachinery, 118, 744-751 (1996)

25. R. Langtry, F. R. Menter, AIAA Jour., 47, 2894-2906 (2009)

26. V. M. Falkner, S. W. Skan, Phil. Mag., 12, 865-896 (1930)

27. J. Fürst, J. Př́hoda, P. Straka, Computing, 95, S163S182 (2013)

28. M. V. Pinson, T. Wang, Jour. Turbomachinery, 122, 301-307, 308-316 (2000)

29. C. C. Koch, L. H. Smith Jr., Jour. Engineering for Power, 98, 411-424 (1976)

30. J. Ulrych, J. Benetka, T. Jelínek, R. Valenta, L. Tajč, Proc. XVIII Symposium on Measuring Techniques in Turbomachinery, Thessaloniki, CD-ROM, 5 p. (2006)

31. M. Kladrubský, Measurement of linear blade cascade VS-33 along the blade height at the spacing 0.7, VZLÚ Praha, Research Report R-5166 (2011)

32. J. Amecke, P. Šafaŕík, Data reduction of wake flow measurements with injection of an other gas, DLRForschungbericht 95-32, Göttingen (1995) 